Codon usage in plant genes

Elizabeth E.Murray ${ }^{1.2 *}$, Jeff Lotzer ${ }^{1}$ and Mary Eberle ${ }^{1}$

${ }^{1}$ Agrigenetics Advanced Sciences Company, 5649 East Buckeye Road, Madison, WI 53713 and

${ }^{2}$ McArdle Laboratory for Cancer Research, University of Wisconsin, Madison, WI 53706, USA

Received October 6, 1988; Accepted December 14, 1988

\begin{abstract}
:
We have examined codon bias in 207 plant gene sequences collected from Genbank and the literature. When this sample was further divided into 53 monocot and 154 dicot genes, the pattern of relative use of synonymous codons was shown to differ between these taxonomic groups, primarily in the use of $G+C$ in the degenerate third base. Maize and soybean codon bias were examined separately and followed the monocot and dicot codon usage patterns respectively. Codon preference in ribulose 1,5 bisphosphate and chlorophyll $\mathrm{a} / \mathrm{b}$ binding protein, two of the most abundant proteins in leaves was investigated. These highly expressed are more restricted in their codon usage than plant genes in general.
\end{abstract}

\title{
Introduction:
}

With the exception of Met and Trp, all amino acids are encoded by two to six synonymous codons. In the majority of species studied to date, an organism's use of synonymous codons is not random (1-5). However, detailed characterization of specific patterns of codon usage have been reported primarily for unicellular organisms, including $E$. coli (6-8), Bacillus (9,10), Agrobacterium (11) and yeast (12-17). The pattern of codon usage in higher eukaryotes has been examined in only a limited number of species, including Crosophila (19) and man (13, 18-21).

In the last three years, a large number of DNA sequences of higher plant genes have been reported, enabling us to extend the initial analyses of plant codon usage previously reported $(13,18,22,23)$. We have used an expanded sample of 207 plant gene sequences to examine some general observations about codon usage.

In general, genes within a taxonomic group exhibit similarities in codon choice, regardless of the function of these genes. Thus an estimate of the overall use of the genetic code by an taxonomic group can be obtained by summing codon frequencies of all its sequenced genes. This species-specific codon choice has been called a "codon dialect" by Ikemura (13). Here we report on the "codon dialect" of 207 plant genes. We have broken this sample down into monocotyledonous and dicotyledonous plants to determine whether these broader taxonomic groups are characterized by different patterns of synonymous codon preference. Finally, we report the codon dialect of maize and soybean, since over 25 genes have been sequenced in each of these agronomically important species.

Bias in codon choice within genes in a single species appears related to the level of expression of the protein encoded by that gene $(6,7,12-18)$. Codon bias is most extreme in highly expressed proteins of $E$. coli and yeast. In these organisms, a strong positive 
correlation has been reported between the abundance of an isoaccepting tRNA species and the favored synonymous codon. In one group of highly expressed proteins in yeast, over $96 \%$ of the amino acids are encoded by only 25 of the 61 available codons (15). These 25 codons are preferred in all sequenced yeast genes, but the degree of preference varies with the level of expression of the genes. Recently, Hoekema and colleagues (24) report that replacement of these 25 preferred codons by minor codons in the 5' end of the highly expressed yeast gene PGK1 results in a decreased level of both protein and mRNA. They conclude that biased codon choice in highly expressed genes enhances translation and is required for maintaining mRNA stability in yeast. The degree of codon bias may be a factor to consider when engineering high expression of heterologous genes in yeast and other systems.

In plants, the ribulose 1,5 bisphosphate small subunit (RuBPC SSU) and chlorophyll a/b binding protein (CAB) gene families encode two of the most abundant proteins in leaves. These genes have been sequenced in a number of different plants, and we have examined their codon usage in detail to determine whether they are more biased than other plant genes.

\section{Data and Methods:}

The 207 plant genes included in the sample are detailed in Tables 1 and 2. Sources for the data were Genbank (release 55) or original publications, referenced in Tables 1 and 2 and listed in the Appendix. Genes for which only genomic sequence was available were included, and introns were removed before codon usage data was generated. Partial sequences available for some genes were included when reading frame could be determined.

Homologous genes in different species, or multigene gene families within a species have been sequenced, including those for zein, glycinin, vicilin, CAB and RuBPC SSU. Multiple sequences of these genes were included in the sample if they differed by a minimum of $10 \%$ in the base composition of their protein coding regions. As a result, this sample may contain some bias towards codon usage in highly expressed genes.

Genbank sequences were extracted using the GENBANK program (25). Codon usage tables were compiled using the program CODONFREQUENCY from the program library of the University of Wisconsin Genetics Computer group (26).

\section{Results:}

Plant genes coding for proteins with a wide variety of functions have now been sequenced. We have tabulated the sequences of 207 plant genes (Tables 1 and 2) from 6 monocot and 36 dicot species. These proteins are present in a wide range of plant tissues at varying levels of expression. However, to date, only a few plant genes encoding rare proteins and/or mRNAs have been sequenced.

We have calculated the codon usage profile of the pooled plant sample and separate codon usage profiles for the monocotyledonous and dicotyledonous groups of plants (Table 3). This division reveals that the relative use of synonymous codons differs between the monocots and the dicots. Since the monocot sample is one third smaller than the dicot sample, we were concerned that the relative abundance of storage protein genes could skew its codon usage profile. Accordingly, we calculated codon usage in the monocots without these genes (Table 3). 
Table 1

Descriptions and sources of 53 monocot genes included in the analysis.

\begin{tabular}{|c|c|c|c|}
\hline GENUS/SPECIES & GDNBANK & PROTEIN & REF \\
\hline \multirow{14}{*}{$\begin{array}{l}\text { Avena sativa } \\
\text { Hordeum vulgare }\end{array}$} & ASTAP3R & Phytochrome 3 & 1 \\
\hline & BLYALR & Aleurain & 2 \\
\hline & BLYAMY1 & $\alpha$ amylase 1 & 3 \\
\hline & BLYAMY2 & $\alpha$ amylase 2 & 3 \\
\hline & BLYCHORD1 & Hordein C & 4 \\
\hline & BLYGLUCB & $\boldsymbol{\beta}$ glucanase & 5 \\
\hline & BLYHORB & B1 hordein & 6 \\
\hline & BLYPAPI & Amylase/protease inhibitor & 7 \\
\hline & BLYTHYAR & Toxin $\alpha$ hordothionin & 8 \\
\hline & BLYUBIQR & Ubiquitin & 9 \\
\hline & & Histone 3 & 10 \\
\hline & & Leaf specific thionin 1 & 11 \\
\hline & & Leaf specific thionin 2 & 11 \\
\hline & & Plastocyanin & 12 \\
\hline \multirow[t]{2}{*}{ Oryza saiva } & RICGLUTG & Glutelin & 13 \\
\hline & & Glutelin & 14 \\
\hline \multirow[t]{10}{*}{ Triticum aestivum } & WHTAMYA & $\alpha$ amylase & 15 \\
\hline & WHTCAB & CAB & 16 \\
\hline & WHTEMR & Em protein & 17 \\
\hline & WHTGIR & gibberellin responsive protein & 18 \\
\hline & WHTGLGB & $\boldsymbol{\gamma}$ gliadin & 19 \\
\hline & WHTGLIABA & $\alpha / \beta$ gliadin Class AII & 20 \\
\hline & WHTGLUT1 & High MW glutenin & 21 \\
\hline & WHTH3 & Histone 3 & 22 \\
\hline & WHTH4091 & Histone 4 & 23 \\
\hline & WATRBCB & RuBPC small subunit & 24 \\
\hline Secale cereale & RYESECGSR & $\boldsymbol{\gamma}$ secalin & 25 \\
\hline \multirow[t]{27}{*}{ Zea mays } & MREA1G & $\begin{array}{l}40.1 \mathrm{kD} \mathrm{A1} \text { protein (NADPH- } \\
\text { dependent reductase) }\end{array}$ & 26 \\
\hline & MEEACTIG & Actin & 27 \\
\hline & MZEADH11F & Alcohol dehydrogenase 1 & 28 \\
\hline & MEEADH2NR & Alcohol dehydrogenase 2 & 28 \\
\hline & MEEALD & Aldolase & 29 \\
\hline & MZEANT & ATP/ADP translocator & 30 \\
\hline & MZEEG2R & Glutelin 2 & 31 \\
\hline & MZEGGST3B & Glutathione $\mathbf{S}$ transferase & 32 \\
\hline & MZEH3C2 & Histone 3 & 33 \\
\hline & MZEH4C14 & Histone 4 & 34 \\
\hline & MZEHSP701 & 70 kD Heat shock protein, exon 1 & 35 \\
\hline & MEDHSP702 & $70 \mathrm{kD}$ Heat shock protein, exon 2 & 35 \\
\hline & MEILHCP & CAB & 36 \\
\hline & MZEMPL3 & Lipid body surface protein L3 & 37 \\
\hline & MEDPEPCR & Phosphoenolyruvate carboxylase & 38 \\
\hline & MRERACS & RuBPC small subunit & 39 \\
\hline & MZESUSYSG & Sucrose synthetase & 40 \\
\hline & MVETPI2 & Triosephosphate isomerase 1 & 41 \\
\hline & MREZ2а20M & $19 \mathrm{kD}$ zein & 42 \\
\hline & MREZZA30M & $19 \mathrm{kD}$ zein & 42 \\
\hline & MZTZZE15A3 & $15 \mathrm{kD}$ zein & 43 \\
\hline & MVEZZE16 & $16 \mathrm{kD}$ zein & 44 \\
\hline & MVAX2E19A & $19 \mathrm{kD}$ zein & 45 \\
\hline & MVAT2521 & 22 kD zein & 46 \\
\hline & M2527522B & $22 \mathrm{kD}$ zein & 46 \\
\hline & & Catalase 2 & 47 \\
\hline & & Regulatory $\mathrm{Cl}$ locus & 48 \\
\hline
\end{tabular}

Data was obtained from GenBank (release 55) or, when no Genbank file name is specified, directly from the published source.

In general, the most important factor in discriminating between monocot and dicot patterns of codon usage is the percentage $\mathrm{G}+\mathrm{C}$ content of the degenerate third base. In monocots, 16 of 18 amino acids favor $\mathrm{G}+\mathrm{C}$ in this position, while dicots only favor $\mathrm{G}+\mathrm{C}$ in 7 of 18 amino acids. 
Table 2

Descriptions and sources of 154 genes dicot included in the analysis.

\begin{tabular}{|c|c|c|c|}
\hline GENUS/ SPECIES & GENBANK & $\begin{array}{r}\text { PROTEIN } \\
\end{array}$ & REF \\
\hline Antimhinum majus & AMACHS & Chalcone synthetase & 49 \\
\hline \multirow[t]{7}{*}{ Arabidopsis thaliana } & ATHADH & Alcohol dehydrogenase & so \\
\hline & АTHН3GA & Histone 3 gene 1 & 51 \\
\hline & ATHH3GB & Histone 3 gene 2 & 51 \\
\hline & ATHH4GA & Histone 4 gene 1 & 51 \\
\hline & ATHLACP1 & $\mathrm{CAB}$ & 52 \\
\hline & ATHTUBA & a tubulin & 53 \\
\hline & & $\begin{array}{l}\text { S-enolpyruvyl4hifate 3-phosphate } 54 \\
\text { synthetase }\end{array}$ & \\
\hline Bertholletia excelsa & & High methionine storage protein & 55 \\
\hline Brassica campestris & & Acyl carrier protein & 56 \\
\hline Brassica napus & BNANAP & Napin & 57 \\
\hline Brassica oleacea & BOLSLSGR & S-locus specific glycoprotein & 58 \\
\hline Canavalia ensiformis & CENCONA & Concanavalin $\mathrm{A}$ & 59 \\
\hline Carica papaya & CPAPAP & Papain & 60 \\
\hline \multicolumn{4}{|l|}{ Chlamdomonas } \\
\hline \multirow[t]{3}{*}{ reinhordtii } & CREC552 & Preapocytochrome & 61 \\
\hline & CRERBCS1 & RuBPC small subunit gene 1 & 62 \\
\hline & CRERBCS2 & RuBPC small subunit gene 2 & 62 \\
\hline Cucuabita pepo & CUCPHT & Phytochrome & 63 \\
\hline \multirow[t]{3}{*}{ Cucumis sativus } & CUSGMS & Glyoxosomal malate synthetase & 64 \\
\hline & CUSLHCPA & CAB & 65 \\
\hline & Cusssu & RuBPC small subunit & 65 \\
\hline \multirow[t]{2}{*}{ Daucus carota } & DAREXT & Extensin & 66 \\
\hline & DAREXTR & $33 \mathrm{kD}$ extensin related protein & 67 \\
\hline Dolichos biflonus & DBILECS & seed lectin & 68 \\
\hline Flaveria minervia & FTRBCR & RuBPC small subunit & 69 \\
\hline \multirow[t]{29}{*}{ Glycine $\max$} & SOY7SAA & 7S storage protein & 70 \\
\hline & SOYACT1G & Actin 1 & 27 \\
\hline & SOYCIIPI & Cll protease inhibitor & 71 \\
\hline & SOYGLYA1A & Glycinin Ala Bx subunits & 72 \\
\hline & SOYGLYAAB & Glycinin ASA4B3 subunits & 73 \\
\hline & SOYGLYAB & Glycinin $A 3 / b 4$ subunits & 74 \\
\hline & SOYGLYR & Glycinin A2B1a subunits & 75 \\
\hline & SOYHSP175 & Low $M W$ heat shock proteins & 76 \\
\hline & SOYLGBI & Leghemoglobin & 77 \\
\hline & SOYLEA & Lectin & 78 \\
\hline & SOYLOX & Lipoxygenase 1 & 79 \\
\hline & SOYNOD20G & $20 \mathrm{kDa}$ nodulin & 80 \\
\hline & SOYNOD23G & $23 \mathrm{kDa}$ nodulin & 81 \\
\hline & SOYNOD2AH & $24 \mathrm{kDa}$ nodulin & 82 \\
\hline & SOYNOD26B & $26 \mathrm{kDa}$ nodulin & 83 \\
\hline & SOYNOD26R & $26 \mathrm{kDa}$ nodulin & 84 \\
\hline & SOYNOD27R & $27 \mathrm{kDa}$ nodulin & 83 \\
\hline & SOYNOD35M & $35 \mathrm{kDa}$ nodulin & 86 \\
\hline & SOYNOD7s & $75 \mathrm{kDa}$ nodulin & 86 \\
\hline & SOYNODR1 & Nodulin C51 & 87 \\
\hline & SOYNODR2 & Nodulin E27 & 87 \\
\hline & SOYPRP1 & Proline rich protein & 88 \\
\hline & SOYRUBP & RuBPC small subunit & 89 \\
\hline & SOYURA & Urease & 90 \\
\hline & SOYHSP26A & Heat shock protein 26A & 91 \\
\hline & & $\begin{array}{l}\text { Nuclear-encoded chloroplast } \\
\text { heat shock protein }\end{array}$ & 92 \\
\hline & & 22 kDa nodulin & 80 \\
\hline & & p1 tubulin & 93 \\
\hline & & P2 tubulin & 93 \\
\hline \multirow[t]{2}{*}{ Gossypium hirsutum } & & Seed $\propto$ globulin (vicilin) & 94 \\
\hline & & Seed $\boldsymbol{\theta}$ globulin (vicilin) & 94 \\
\hline Helianchus annus & HNNRUBCS & $\begin{array}{l}\text { RuBPC small subunit } \\
2 S \text { albumin seed storage protein }\end{array}$ & $\begin{array}{l}95 \\
96\end{array}$ \\
\hline Ipomoea batatas & & Wound-induced catalase & 97 \\
\hline \multirow[t]{2}{*}{ Lemna gibba } & LGLAB19 & CAB & 98 \\
\hline & LGIRSBPC & RuBPC small subunit & 99 \\
\hline Lupinus luteus & LUPLBR & leghemoglobin I & 100 \\
\hline
\end{tabular}




\begin{tabular}{|c|c|c|c|}
\hline GENUS/ SPECIES & GENBANK & PROTEIN & REF \\
\hline \multicolumn{4}{|l|}{ Lycopersicon } \\
\hline \multirow{15}{*}{ esculentum } & TOMITHYYR & Ethylene biosynthesis protein & 102 \\
\hline & TOMPG2AR & Polygalacturonase-2a & 103 \\
\hline & TOMPSI & Tomato photosystem I protein & 104 \\
\hline & TOMRBCSA & RuBPC small subunit & 105 \\
\hline & TOMIRECSB & RuBPC small subunit & 105 \\
\hline & TOMRBCSC & RuBPC small subunit & 105 \\
\hline & TOMRBCSD & RuBPC small subunit & 106 \\
\hline & TOMRRD & Ripening related protein & 107 \\
\hline & TOMWIPIG & $\begin{array}{l}\text { Wound induced proteinase } \\
\text { inhibitor I }\end{array}$ & 108 \\
\hline & TOMWIPII & $\begin{array}{l}\text { Wound induced proteinase } \\
\text { inhibitor II }\end{array}$ & 109 \\
\hline & & CAB 1A & 110 \\
\hline & & CAB 1B & 110 \\
\hline & & CAB 3C & 110 \\
\hline & & CAB 4 & 111 \\
\hline & & CAB 5 & 111 \\
\hline Medicago sativa & ALFLB3R & Leghemoglobin III & 112 \\
\hline $\begin{array}{l}\text { Mesembryanthemum } \\
\text { cystallinum }\end{array}$ & & RuBPC small subunit & 113 \\
\hline \multicolumn{4}{|l|}{ Nicotiana } \\
\hline \multirow[t]{3}{*}{ plumbaginifolia } & TOBATP21 & $\begin{array}{l}\text { Mitochondrial ATP synthase } \\
\text { subunit }\end{array}$ & 114 \\
\hline & & Nitrate reductase & 115 \\
\hline & & Glutamine synthetase & 116 \\
\hline \multirow[t]{10}{*}{ Nicotiana tabacum } & TOBECH & Endochitinase & 117 \\
\hline & TOBGAPA & A subunit of chloroplast G3PD & 118 \\
\hline & TOBGAPB & B subunit of chloroplast G3PD & 118 \\
\hline & TOBGAPC & C subunit of chloroplast G3PD & 118 \\
\hline & TOBPRIAR & Pathogenesis related protein 1a & 119 \\
\hline & TOBPR1CR & Pathogenesis-related protein 1c & 119 \\
\hline & TOBPRPR & Pathogenesis related protein $1 \mathrm{~b}$ & 120 \\
\hline & TOBPXDL & Peroxidase & 121 \\
\hline & TOBRBFCO & RuBPC small subunit & 122 \\
\hline & TOBTHAUR & $\begin{array}{l}\text { TMV-induced protein homologous } \\
\text { to thaumatin }\end{array}$ & 123 \\
\hline Perseus americana & AVOCEL & Cellulase & 124 \\
\hline \multicolumn{4}{|l|}{ Petroselinum } \\
\hline horrense & PHOCHL & Chalcone synthase & 125 \\
\hline \multirow[t]{11}{*}{ Peturia sp. } & PETCAB13 & CAB 13 & 126 \\
\hline & PETCAB22L & CAB 22L & 126 \\
\hline & PETCAB22R & CAB 22R & 126 \\
\hline & PETCAB25 & CAB 25 & 126 \\
\hline & PETCAB37 & CAB 37 & 127 \\
\hline & PETCAB91R & CAB 91R & 127 \\
\hline & PUTCHSR & Chalcone synthase & 128 \\
\hline & PETGCR1 & Glycine-rich protein & 129 \\
\hline & PETRECS & RuBPC small subunit & 130 \\
\hline & PATRECS11 & RuBPC small subunit & 130 \\
\hline & & $70 \mathrm{kDa}$ heat shock protein & 131 \\
\hline \multirow[t]{11}{*}{ Phaseolus vulgaris } & PHVCHM & Chitinase & 132 \\
\hline & PHVDLDCA & Phytobemagelutinin E & 133 \\
\hline & PHVDLECB & Phytohemagegutinin L & 133 \\
\hline & PAVGSR1 & Glutamine synthetase 1 & 134 \\
\hline & PHVGSR2 & Glutamine synthetase 2 & 134 \\
\hline & PHVLA & Leghemogjobin & 135 \\
\hline & PHVLCT & Lectin & 136 \\
\hline & PHVPAL & Phenylalanine ammonia lyase & 137 \\
\hline & PHVPHASAR & a phaseolin & 138 \\
\hline & PHVPHASBR & $\begin{array}{l}\text { B phaseolin } \\
\text { Arcelin seed protein }\end{array}$ & $\begin{array}{l}138 \\
139\end{array}$ \\
\hline & & Chalcone synthase & 140 \\
\hline \multirow[t]{3}{*}{ Pisum sativum } & PEAALB2 & Seed albumin & 141 \\
\hline & PEACABEO & $\mathbf{C A B}$ & 142 \\
\hline & PEAGSR1 & Glutamine synthetase (nodule) & 143 \\
\hline
\end{tabular}




\begin{tabular}{|c|c|c|c|}
\hline GENUS/ SPECIES & GENBANK & PROTEIN & REF \\
\hline & PEALECA & Lectin & 144 \\
\hline & PEALEGA & Legumin & 145 \\
\hline & PEARUBPS & RuBPC small subunit & 146 \\
\hline & PEAVIC2 & Vicilin & 147 \\
\hline & PEAVICA & Vicilin & 147 \\
\hline & PEAVIC7 & Vicilin & 147 \\
\hline & & Alcohol dehydrogenase 1 & 148 \\
\hline & & Glutamine synthetase (leaf) & 143 \\
\hline & & Glutamine synthetase (root) & 143 \\
\hline & & Histone 1 & 149 \\
\hline & & $\begin{array}{l}\text { Nuclear encoded chloroplast } \\
\text { heat shock protein }\end{array}$ & 92 \\
\hline Raphanus sativus & & RuBPC small subunit & 150 \\
\hline \multirow{3}{*}{ Ricinus communis } & RCCAGG & Agglutinin & 151 \\
\hline & RCCRICIN & Ricin & 152 \\
\hline & RCCICLA & Isocitrate lyase & 153 \\
\hline \multirow[t]{2}{*}{ Silene pratensis } & SIPFDX & Ferrodoxin precursor & 154 \\
\hline & SIPPCY & Plastocyanin precursor & 155 \\
\hline Sinapis alba & SALGAPDH & Nuclear gene for G3PD & 156 \\
\hline \multirow[t]{6}{*}{ Solanum tuberosum } & POTPAT & Patatin & 157 \\
\hline & POTINHWI & $\begin{array}{l}\text { Wound-induced proteinase } \\
\text { inhibitor }\end{array}$ & 158 \\
\hline & POTLS1G & $\begin{array}{l}\text { Light-inducible tissue specific } \\
\text { ST-LS1 gene }\end{array}$ & 159 \\
\hline & POTPI2G & $\begin{array}{l}\text { Wound-induced proteinase } \\
\text { inhibitor II }\end{array}$ & 160 \\
\hline & POTRBCS & RuBPC small subunit & 161 \\
\hline & & Sucrose synthetase & 162 \\
\hline \multirow[t]{6}{*}{ Spinacia oleracea } & SPLACPI & Acyl carrier protein I & 163 \\
\hline & SPIOEC16 & $\begin{array}{l}16 \mathrm{kDa} \text { photosynthetic } \\
\text { oxygen-evolving protein }\end{array}$ & 164 \\
\hline & SPIOEC23 & $\begin{array}{l}23 \mathrm{kDa} \text { photosynthetic } \\
\text { oxygen-evolving protein }\end{array}$ & 165 \\
\hline & SPIPCG & Plastocyanin & 165 \\
\hline & SPIPS33 & $\begin{array}{l}33 \mathrm{kDa} \text { photosynthetic water } \\
\text { oxidation complex precursor }\end{array}$ & 166 \\
\hline & & Glycolate oxidase & 167 \\
\hline \multirow[t]{3}{*}{ Vicia faba } & VFALBA & Leghemoglobin & 168 \\
\hline & VFALEBA & Legumin B & 169 \\
\hline & & Vicillin & 170 \\
\hline
\end{tabular}

Data was obtained from GenBank (release 55) or, when no Genbank file name is specified, तirectly from the published source.

Table 3

Codon usage in pooled sequences of higher plant genes.

\begin{tabular}{|c|c|c|c|c|c|c|c|c|c|}
\hline \multirow[b]{2}{*}{ AmAcid } & \multirow[b]{2}{*}{ Codon } & \multicolumn{2}{|c|}{$\begin{array}{l}\text { Plants } \\
n=207\end{array}$} & \multicolumn{2}{|c|}{$\begin{array}{c}\text { Dicots } \\
n=154\end{array}$} & \multicolumn{2}{|c|}{$\begin{array}{c}\text { Monocots } \\
\mathrm{n}=\mathbf{5 3}\end{array}$} & \multicolumn{2}{|c|}{$\begin{array}{c}\text { Monocots } \\
\text { No Storage } \\
\text { Proteins } \\
\mathbf{n}=39\end{array}$} \\
\hline & & No. & $\%$ & No. & $\%$ & No. & $\%$ & No. & $\%$ \\
\hline Ghy & GGG & 731 & $\overline{15}$ & 749 & $\overline{12}$ & 282 & $\overline{21}$ & 267 & $\overline{22}$ \\
\hline Gly & GGA & 1629 & 32 & 1399 & 38 & 230 & 17 & 193 & 16 \\
\hline Gly & GGT & 1477 & 29 & 1231 & 34 & 246 & 18 & 207 & 17 \\
\hline Gly & GGC & 1179 & 24 & 596 & 16 & 583 & 44 & 543 & 45 \\
\hline Glu & $\overline{\text { GAG }}$ & $\overline{2102}$ & 57 & 1498 & 51 & 604 & 75 & 568 & 79 \\
\hline Glu & GAA & 1616 & 43 & 1419 & 49 & 197 & 25 & 154 & 21 \\
\hline Asp & GAT & 1458 & 50 & 1269 & 58 & 189 & 27 & 16 & 24 \\
\hline Asp & GAC & 1441 & 50 & 927 & 42 & 514 & 73 & 503 & 76 \\
\hline Val & GTG & 1354 & 31 & 956 & 29 & 398 & 36 & 338 & 37 \\
\hline Val & GTA & 491 & 11 & 402 & 12 & 89 & 8 & 52 & 6 \\
\hline Val & GTT & 1478 & 34 & 1270 & 39 & 208 & 19 & 154 & 17 \\
\hline Val & GTC & 1045 & 24 & 642 & 20 & 403 & 37 & 362 & \\
\hline
\end{tabular}




\begin{tabular}{|c|c|c|c|c|c|c|c|c|c|}
\hline \multirow[b]{2}{*}{ AmAcid } & \multirow[b]{2}{*}{ Codon } & \multicolumn{2}{|c|}{ Plants } & \multicolumn{2}{|c|}{ Dicots } & \multicolumn{2}{|c|}{ Monocots } & \multicolumn{2}{|c|}{$\begin{array}{l}\text { Monocots } \\
\text { No Storage } \\
\text { Protèins }\end{array}$} \\
\hline & & No. & $\%$ & No. & $\%$ & No. & $\%$ & No. & $\%$ \\
\hline Ala & GCG & 546 & 11 & 211 & 6 & 335 & 22 & 284 & $\overline{24}$ \\
\hline Ala & GCA & 1156 & 22 & 916 & 25 & 240 & 16 & 137 & 12 \\
\hline Ala & GCT & 1901 & 37 & 1530 & 42 & 371 & 24 & 254 & 21 \\
\hline Ala & GCC & 1548 & 30 & 960 & 27 & 588 & 38 & 510 & 43 \\
\hline Arg & AGG & 742 & 26 & 540 & 25 & 202 & 26 & 163 & 25 \\
\hline Arg & AGA & 707 & 24 & 633 & 30 & 74 & 9 & 50 & 8 \\
\hline Ser & AGT & 581 & 13 & 493 & 14 & 88 & 8 & 51 & 6 \\
\hline Ser & AGC & 887 & 20 & 605 & 18 & 282 & 26 & 225 & 27 \\
\hline Lys & AAG & 2241 & 66 & 1600 & 61 & 641 & 86 & 609 & 86 \\
\hline Lys & AAA & 1139 & 34 & 1034 & 39 & 105 & 14 & 98 & 14 \\
\hline Asn & AAT & 1137 & 41 & 982 & 45 & 155 & 25 & 106 & 23 \\
\hline Asn & AAC & 1646 & 59 & 1188 & S5 & 458 & 75 & 356 & 77 \\
\hline Met & ATG & 1356 & 100 & 982 & 100 & 374 & 100 & 311 & 100 \\
\hline Ile & ATA & 505 & 16 & 419 & 18 & 86 & 11 & 48 & 8 \\
\hline Ile & ATT & 1241 & 40 & 1051 & 45 & 190 & 24 & 128 & 21 \\
\hline Ile & ATC & 1374 & 44 & 873 & 37 & 501 & 65 & 433 & 71 \\
\hline Thr & $\overline{\mathrm{ACG}}$ & 343 & 11 & 184 & 8 & 159 & 21 & 146 & 22 \\
\hline Thr & ACA & 745 & 24 & 636 & 27 & 109 & 14 & 73 & 11 \\
\hline Thr & ACT & 990 & 31 & 842 & 35 & 148 & 19 & 116 & 18 \\
\hline Thr & $\mathrm{ACC}$ & 1082 & 34 & 721 & 30 & 361 & 46 & 319 & 49 \\
\hline $\mathrm{Trp}$ & TGG & 790 & 100 & 605 & 100 & 185 & 100 & 171 & 100 \\
\hline End & TGA & 68 & 33 & 50 & 33 & 18 & 34 & 15 & 37 \\
\hline Cys & TGT & 432 & 40 & 338 & 44 & 94 & 30 & 69 & 27 \\
\hline Cys & TGC & 647 & 60 & 423 & 56 & 224 & 70 & 185 & 73 \\
\hline End & TAG & 48 & 24 & 29 & 19 & 19 & 36 & 11 & 27 \\
\hline End & TAA & 88 & 43 & 72 & 48 & 16 & 30 & 14 & 35 \\
\hline Tyr & TAT & 743 & 37 & 630 & 43 & 113 & 21 & 68 & 16 \\
\hline Tyr & TAC & 1267 & 63 & 838 & 57 & 429 & 79 & 354 & 84 \\
\hline Leu & TTG & 1185 & 22 & 965 & 26 & 220 & 14 & 108 & 9 \\
\hline Leu & TTA & 412 & 8 & 363 & 10 & 49 & 3 & 19 & 2 \\
\hline Phe & TTT & 1047 & 40 & 887 & 45 & 160 & 25 & 95 & 20 \\
\hline Phe & TTC & 1597 & 60 & 1106 & 55 & 491 & 75 & 392 & 80 \\
\hline Ser & TCG & 343 & 8 & 192 & 6 & 151 & 14 & 139 & 17 \\
\hline Ser & TCA & 768 & 17 & 649 & 19 & 119 & 11 & 67 & 8 \\
\hline Ser & TCT & 1009 & 22 & 844 & 25 & 165 & 15 & 112 & 13 \\
\hline Ser & TCC & 896 & 20 & 621 & 18 & 275 & 26 & 237 & 29 \\
\hline Arg & CGG & 198 & 7 & 95 & 5 & 103 & 13 & 94 & 14 \\
\hline Arg & CGA & 214 & 7 & 181 & 8 & 33 & 4 & 23 & 3 \\
\hline Arg & Crit & 534 & 18 & 441 & 21 & 93 & 12 & 67 & 10 \\
\hline Arg & $\mathrm{Cr}$ C & 520 & 18 & 241 & 11 & 279 & 36 & 268 & 40 \\
\hline Gln & $\widehat{\mathrm{CAG}}$ & 1465 & 43 & 787 & 41 & 678 & 46 & 457 & 60 \\
\hline Gln & CAA & 1912 & 57 & 1125 & 59 & 787 & 54 & 305 & 40 \\
\hline $\mathrm{His}$ & CAT & 575 & 48 & 465 & 54 & 110 & 33 & 85 & 30 \\
\hline His & CAC & 625 & 52 & 398 & 46 & 227 & 67 & 202 & 70 \\
\hline Leu & CTG & 792 & 15 & 347 & 9 & 445 & 28 & 371 & 33 \\
\hline Leu & CTA & 434 & 8 & 281 & 8 & 153 & 9 & 59 & 5 \\
\hline Leu & CTT & 1273 & 24 & 1032 & 28 & 241 & 15 & 151 & 13 \\
\hline Leu & CTC & 1189 & 22 & 691 & 19 & 498 & 31 & 434 & 38 \\
\hline Pro & CCG & 492 & 13 & 236 & 9 & 256 & 23 & 224 & 30 \\
\hline Pro & CCA & 1507 & 39 & 1126 & 42 & 381 & 34 & 202 & 27 \\
\hline Pro & $\mathrm{CCT}$ & 1063 & 28 & 874 & 32 & 189 & 17 & 118 & 15 \\
\hline Pro & $\mathrm{CCC}$ & 755 & 20 & 469 & 17 & 286 & 26 & 212 & 28 \\
\hline
\end{tabular}

$\mathrm{n}=$ the number of DNA sequences in the sample. No. is the number occurrences of a given codon in the sample. $\%$ is the percent occurrence for each codon within a given amino acid in the sa.nple. (See text for description of the samples). 
Table 4

Codon usage in pooled sequences of higher plant genes.

\begin{tabular}{|c|c|c|c|c|c|c|c|c|c|}
\hline \multirow[b]{2}{*}{ AmAcid } & \multirow[b]{2}{*}{ Codon } & \multicolumn{2}{|c|}{$\begin{array}{c}\text { Soybean } \\
n=29\end{array}$} & \multicolumn{2}{|c|}{$\begin{array}{l}\text { Maize } \\
n=26\end{array}$} & \multicolumn{2}{|c|}{$\begin{array}{c}\text { CAB } \\
n=17\end{array}$} & \multicolumn{2}{|c|}{$\begin{array}{c}\text { RuBP SSU } \\
n=20\end{array}$} \\
\hline & & No. & $\%$ & No. & $\%$ & No. & $\%$ & & $\%$ \\
\hline Gly & 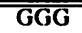 & 90 & $\overline{16}$ & 95 & 16 & $\overline{42}$ & $\overline{8}$ & 16 & \\
\hline Gly & GGA & 189 & 33 & 78 & 13 & 167 & 32 & 95 & \\
\hline Gily & GGT & 193 & 33 & 129 & 21 & 196 & 37 & 32 & 1 \\
\hline Gly & GGC & 102 & 18 & 302 & 50 & 118 & 23 & 43 & 2 \\
\hline Glu & $\overline{\text { GAG }}$ & 310 & 51 & 368 & 81 & 178 & 71 & 139 & 7 \\
\hline Glu & GAA & 301 & 49 & 84 & 19 & 73 & 29 & 49 & \\
\hline Asp & GAT & 244 & 62 & 87 & 24 & 53 & 29 & 39 & \\
\hline Asp & GAC & 150 & 38 & 277 & 76 & 128 & 71 & 79 & 6 \\
\hline Val & GTG & 219 & 37 & 227 & 40 & 62 & 21 & 93 & 36 \\
\hline Val & GTA & 77 & 13 & 36 & 6 & 24 & 8 & 7 & \\
\hline Val & GTT & 227 & 38 & 99 & 17 & 118 & 39 & 87 & 33 \\
\hline Val & GTC & 75 & 12 & 209 & 37 & 96 & 32 & 73 & 20 \\
\hline Ala & (GCG & 42 & 8 & 211 & 24 & 26 & 5 & 16 & \\
\hline Ala & GCA & 170 & 30 & 115 & 13 & 61 & 12 & 42 & 1 \\
\hline Ala & GCT & 208 & 37 & 237 & 27 & 225 & 45 & 110 & 50 \\
\hline Ala & GCC & 139 & 25 & 324 & 36 & 192 & 38 & 125 & 43 \\
\hline Arg & AGG & 88 & 22 & 109 & 26 & 21 & 15 & 17 & 12 \\
\hline Arg & AliA & 119 & 30 & 28 & 7 & 33 & 24 & 31 & 2 \\
\hline Ser & AG;T & 117 & 18 & 29 & 5 & 15 & 5 & 21 & \\
\hline Ser & AGC & 129 & 20 & 150 & 28 & 84 & 27 & 56 & 22 \\
\hline I.ys & AG & 278 & 58 & 367 & 90 & 186 & 85 & 176 & 85 \\
\hline Lys & AAA & 204 & 42 & 43 & 10 & 34 & 15 & 30 & 15 \\
\hline Asn & AAT & 168 & 40 & 56 & 19 & 52 & 30 & 35 & 26 \\
\hline Asn & AAC & 248 & 60 & 246 & 81 & 119 & 70 & 102 & 74 \\
\hline Met & ATG & 184 & 100 & 210 & 100 & 111 & 100 & 115 & 100 \\
\hline Ile & TA & 109 & 24 & 35 & 8 & 10 & 6 & 1 & 1 \\
\hline Ile & IT & 219 & 49 & 100 & 24 & 61 & 40 & 63 & 43 \\
\hline Ile & TC & 118 & 27 & 284 & 68 & 83 & 54 & 83 & 56 \\
\hline Thr & $\overline{C G}$ & 29 & 7 & 114 & 26 & 10 & 6 & 5 & 3 \\
\hline Thr & CA & 128 & 29 & 48 & 11 & 35 & 22 & 21 & 13 \\
\hline Thr & & 151 & 35 & 72 & 16 & 61 & 3 & 59 & 36 \\
\hline Thr & & 124 & 29 & 212 & 47 & 54 & 34 & 79 & 48 \\
\hline Trp & (GG & 82 & 100 & 84 & 100 & 99 & 100 & 86 & 100 \\
\hline End & BA & 5 & 18 & 7 & 26 & 15 & 88 & 2 & 11 \\
\hline Cys & TGT & 63 & 40 & 29 & 21 & 16 & 39 & 7 & 9 \\
\hline Cys & TGC & 95 & 60 & 110 & 79 & 25 & 61 & 72 & 91 \\
\hline End & $\overline{\text { TAG }}$ & 9 & 32 & 14 & 52 & 0 & 0 & 1 & 5 \\
\hline End & AA & 14 & 50 & 6 & 22 & 2 & 12 & 16 & 84 \\
\hline Tyr & $4 T$ & 135 & 49 & 38 & 14 & 23 & 19 & 17 & 10 \\
\hline Tyr & AC & 139 & 51 & 240 & 86 & 99 & 81 & 151 & 90 \\
\hline Leu & TTG & 175 & 24 & 116 & 13 & 118 & 30 & 79 & 36 \\
\hline Let & TA & 79 & 11 & 28 & 3 & 15 & 4 & 6 & 3 \\
\hline Phe & TT & 166 & 46 & 69 & 20 & 106 & 40 & 32 & 20 \\
\hline Phe & TTC & 193 & 54 & 278 & 80 & 160 & 60 & 125 & 80 \\
\hline Ser & TCG & 39 & 6 & 89 & 16 & 17 & 5 & 10 & 4 \\
\hline Ser & CA & 125 & 19 & 56 & 10 & 46 & 15 & 48 & 19 \\
\hline Ser & CT & 140 & 22 & 75 & 14 & 83 & 26 & 33 & 13 \\
\hline Ser & TCC & 94 & 15 & 145 & 27 & 69 & 22 & 89 & 34 \\
\hline Arg & GG & 17 & 4 & 54 & 13 & 7 & 5 & 1 & 1 \\
\hline Arg & CGA & 41 & 10 & 13 & 3 & 6 & 4 & 3 & 2 \\
\hline Arg & CGT & 70 & 18 & 45 & 11 & 50 & 36 & 48 & 33 \\
\hline Arg & CGC & 64 & 16 & 165 & 40 & 20 & 15 & 44 & 31 \\
\hline Gin & CAG & 181 & 41 & 311 & 59 & 36 & 37 & 75 & 51 \\
\hline Gin & CAA & 261 & 59 & 219 & 41 & 60 & 62 & 73 & 49 \\
\hline His & CAT & 124 & 63 & 49 & 29 & 16 & 32 & 4 & 18 \\
\hline $\mathrm{His}$ & CAC & 73 & 37 & 122 & 71 & 34 & 68 & 18 & 82 \\
\hline
\end{tabular}




\begin{tabular}{|ll|rr|rr|rr|rr|}
\hline & & \multicolumn{2}{|c|}{ Soybean } & \multicolumn{2}{c|}{ Maize } & \multicolumn{2}{c|}{ CAB } & \multicolumn{2}{c|}{ RuBP SSU } \\
AmAcid & Codon & \multicolumn{1}{|c|}{ No. } & \multicolumn{1}{c|}{$\%$} & \multicolumn{1}{c|}{ No. } & $\%$ & No. & $\%$ & No. & $\%$ \\
\hline Leu & CTG & 75 & 10 & 289 & 31 & 29 & 7 & 27 & 12 \\
Leu & CTA & 60 & 8 & 78 & 9 & 6 & 2 & 9 & 4 \\
Leu & CTT & 184 & 26 & 147 & 16 & 134 & 34 & 56 & 25 \\
Leu & CTC & 148 & 21 & 261 & 28 & 88 & 23 & 43 & 20 \\
\hline Pro & CCG & 55 & 8 & 149 & 27 & 29 & 10 & 13 & 6 \\
Pro & CCA & 346 & 47 & 126 & 23 & 137 & 47 & 72 & 34 \\
Pro & CCT & 236 & 32 & 109 & 20 & 73 & 25 & 60 & 29 \\
Pro & CCC & 95 & 13 & 164 & 30 & 54 & 18 & 66 & 31 \\
\hline
\end{tabular}

$\mathbf{n}=$ the number of DNA sequences in the sample. No. is the number occurrences of a given codon in the sample. $\%$ is the percent occurrence for each codon within a given amino acid in the sample. (See text for description of the samples).

The $\mathrm{G}$ ending codons for Thr, Pro, Ala and Ser are avoided in both monocots and dicots because they contain $\mathrm{C}$ in codon position II. The CG dinucleotide is strongly avoided in plants (23) and other eukaryotes (27), possibly due to regulation involving methylation. In dicots, XCG is always the least favored codon, while in monocots this is not the case. The doublet TA is also avoided in codon positions II and III in most eukaryotes (27), and this is true of both monocots and dicots.

Grantham and colleagues (18) have developed two codon choice indices to quantify CG and TA doublet avoidance in codon positions II and III. XCG/XCC is the ratio of codons having $\mathrm{C}$ as base II of $\mathrm{G}$-ending to $\mathrm{C}$-ending triplets, while XTA/XTT is the ratio of Aending to $\mathrm{T}$-ending triplets with $\mathrm{T}$ as the serond base. These indices have been calculated for the plant data in this paper (Table 5) and support the conclusion that monocot and dicot species differ in their use of these dinucleotides. This pattern of synonymous codon usage is not dependent on the inclusion of storage protein genes in the monocot sample, since the pooled codon usage data for monocots without storage proteins is even less like the dicot pattern (Table 3). Not surprisingly, the pooled plant sample resembles the dicot pattern more than that of monocots, since almost three times as many dicot sequences as monocot sequences were available.

For two species, soybean and maize, larger sequence samples were available (29 and 28 genes respectively), so that species- specific codon usage profiles could be calculated (Table 4). Not surprisingly, the maize codon usage pattern resembles that of monocots in general, since these sequences represent over half of the monocot sequences available. The codon profile of the maize subsample is even more strikingly biased in its preference for $G+C$ in

Table 5

Avoidance of CG and UA doublets in codons position II-III.

\begin{tabular}{|lcccccccr|}
\hline Group & Plants & Dicots & Monocots & $\begin{array}{c}\text { Monocots } \\
\text { no storage } \\
\text { protein }\end{array}$ & Maize & Soybean & RuBPC SSU & CAB \\
\hline XCG/XCC & 40 & 30 & 61 & 62 & 67 & 37 & 18 & 22 \\
XTA/XTT & 37 & 35 & 47 & 34 & 43 & 41 & 9 & 13 \\
\hline
\end{tabular}

XCG/XCC and XTA/XAA values are multiplied by 100 . 


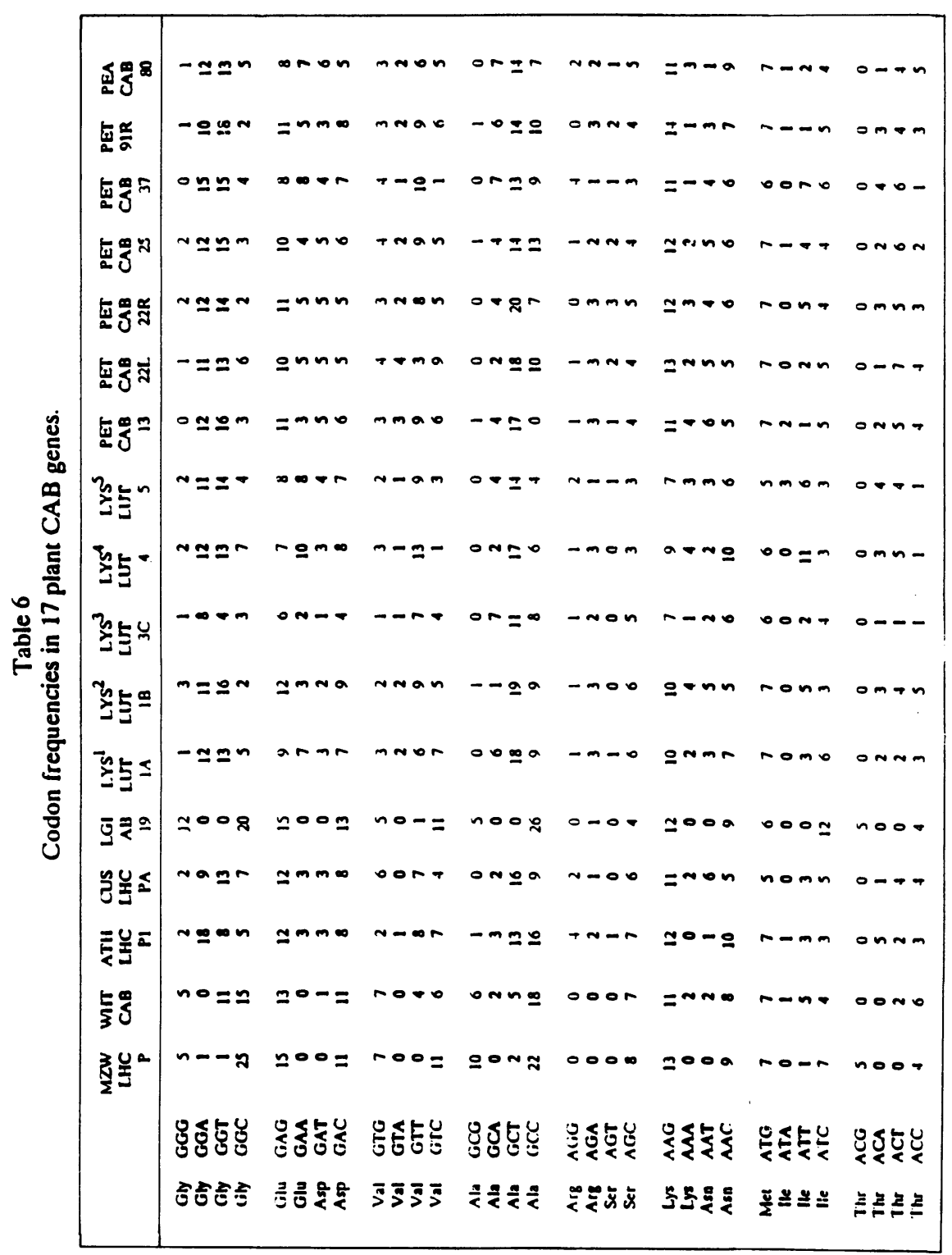




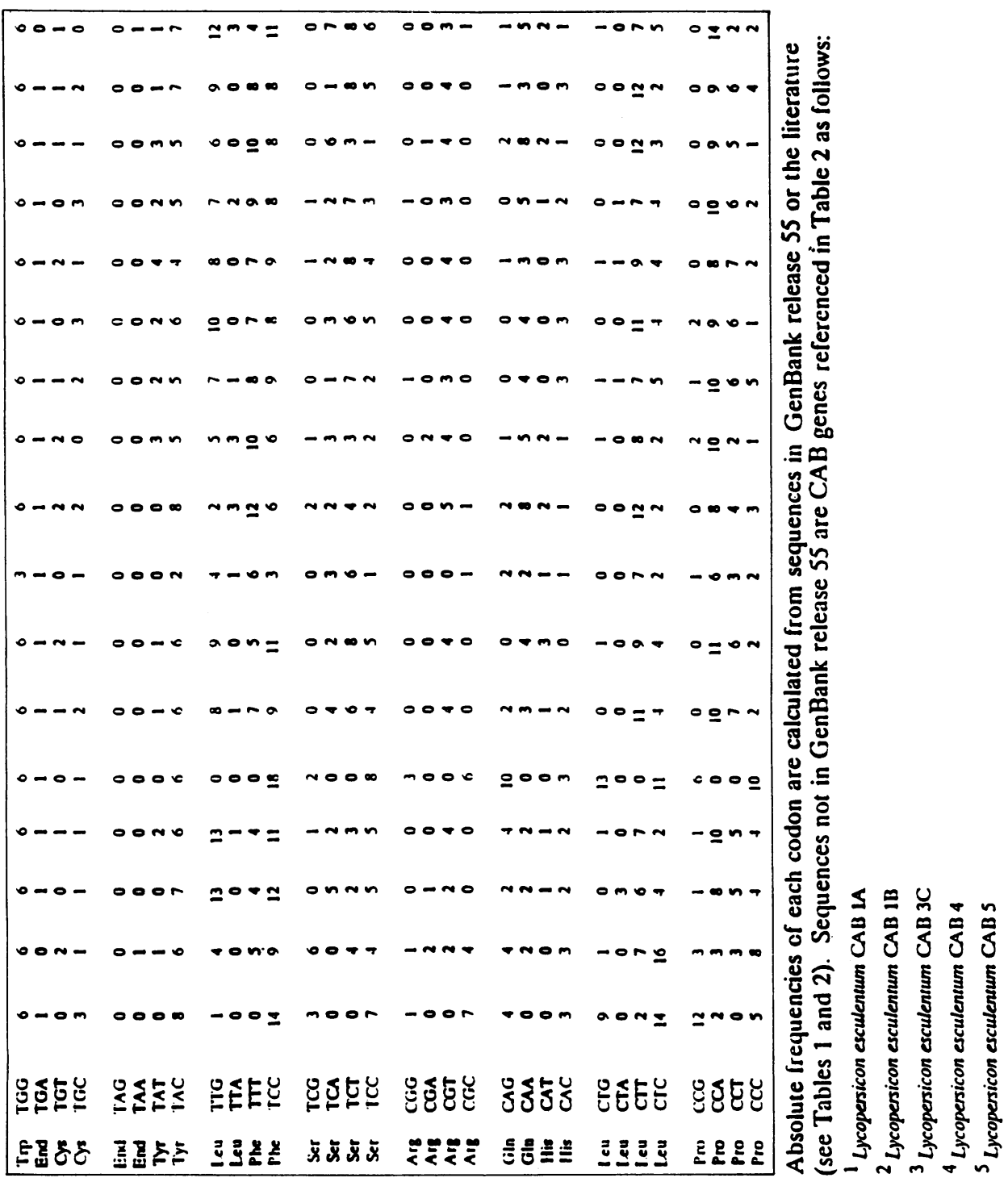




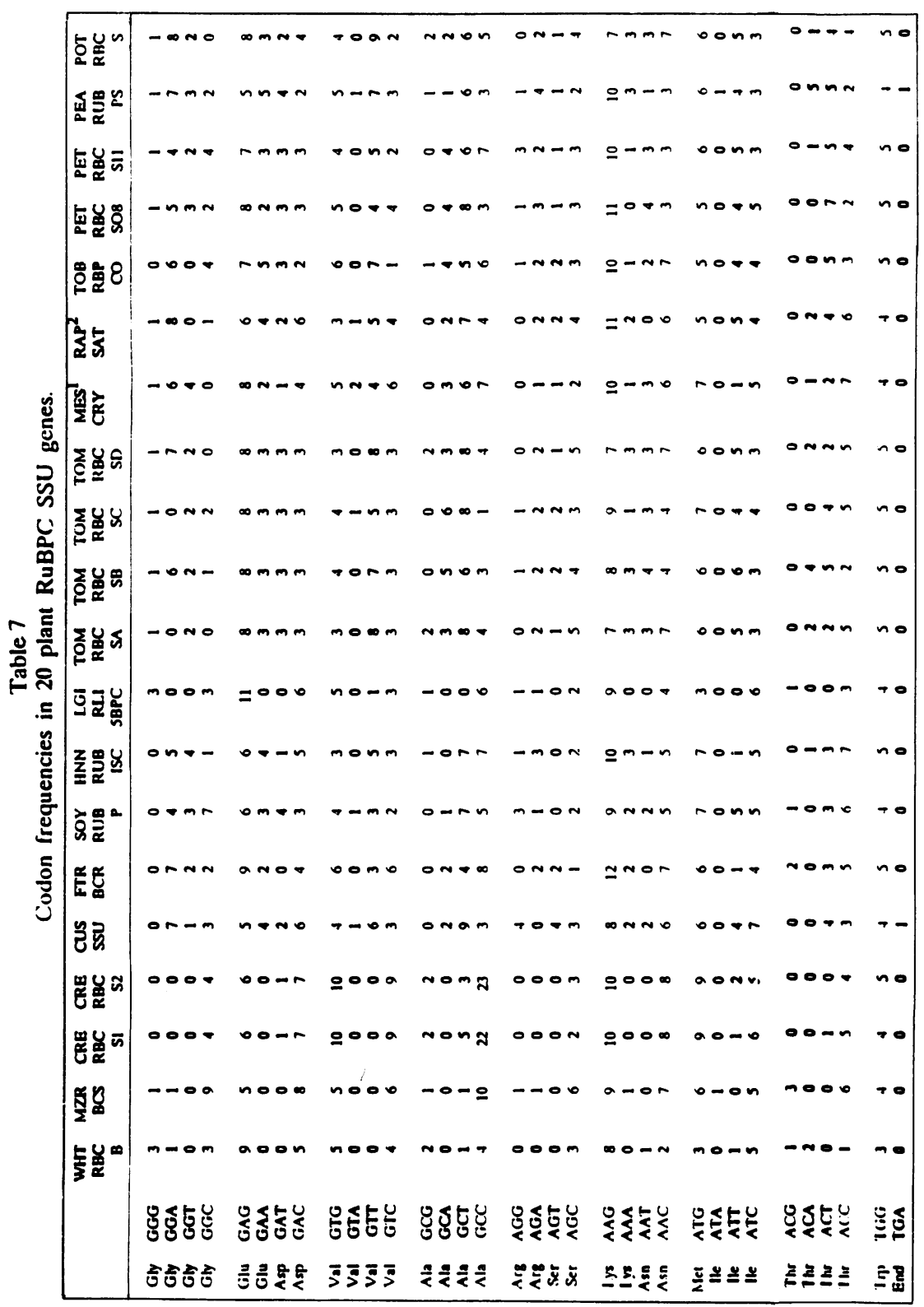




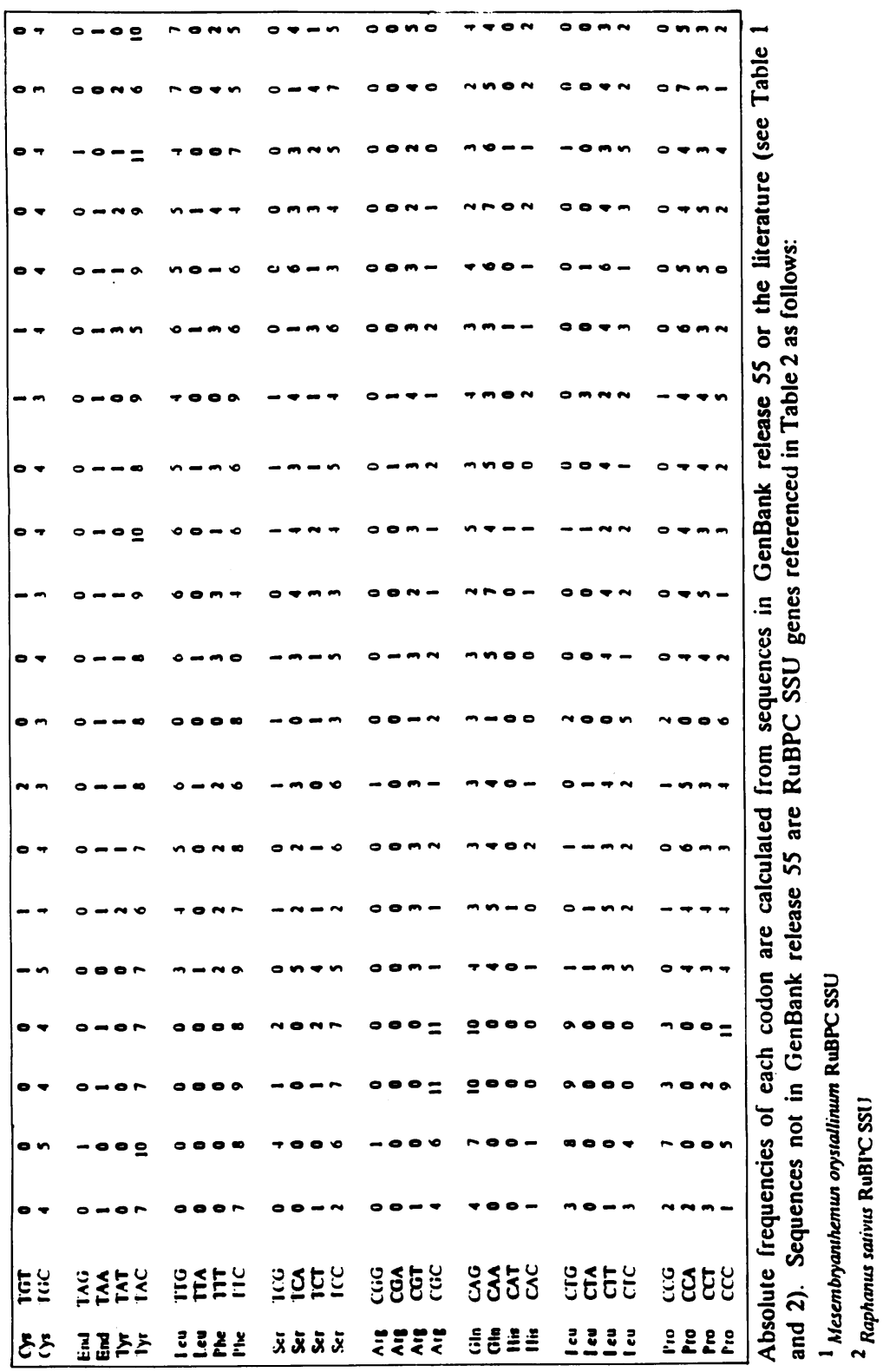


codon position III. However, the soybean codon usage pattern is almost identical to the general dicot pattern, even though it represents a much smaller portion of the entire dicot sample.

In order to determine whether the coding strategy of highly expressed genes such as RuBPC SSU and CAB is more biased than that of plant genes in general, we calculated codon usage profiles for subsets of these genes (20 and 17 sequences respectively) (Table 4). The RuBPC SSU and CAB pooled samples are characterized by stronger avoidance of the codons XCG and XTA than in the larger monocot and dicot samples (Tables 4 and 5). Although most of the genes in these subsamples are dicot in origin (17/20 and 15/17), their codon profile resembles that of the monocots in that $\mathrm{G}+\mathrm{C}$ is preferred in the degenerate base III.

The use of pooled data for highly expressed genes may obscure identification of speciesspecific patterns in codon choice. Therefore, we have tabulated the codon choices of individual genes for RuBPC SSU (Table 6) and CAB (Table 7). The preferred codons of the maize and wheat genes for RuBPC SSU and CAB are more restricted in general than are those of the dicot species. Matsuoka et al. (28) noted the extreme codon bias of the maize RUBPC SSU gene as well as two other highly expressed genes in maize leaves, CAB and phosphoenolpyruvate carboxylase. These genes almost completely avoid the use of $\mathrm{A}+\mathrm{T}$ in codon position III, although this codon bias was not as pronounced in non-leaf proteins such as ADH, zein $22 \mathrm{kDa}$ subunit, sucrose synthetase and ATP/ADP translocator. Since the wheat SSU and CAB genes have a similar pattern of codon preference, this may reflect a common monocot pattern for these highly expressed genes in leaves. The CAB gene for Lemna and the RuBPC SSU genes for Chlamdomonas share a similar extreme preference for $\mathrm{G}+\mathrm{C}$ in codon position III.

In dicot $\mathrm{CAB}$ genes, however, $\mathrm{A}+\mathrm{T}$ degenerate bases are preferred by some synonymous codons (e.g. GCT for Ala, CTT for Leu, GGA and GGT for Gly). In general the G+C preference in position III is less pronounced for both RuBPC SSU and CAB genes in dicots than in monocots.

\section{Discussion:}

Because of the degenerate nature of the genetic code, only part of the variation contained in a gene is expressed in its protein. It is clear that variation between degenerate base frequencies is not a neutral phenomenon since systematic codon preferences have been reported for bacterial, yeast and mammalian genes. Analysis of a large group of plant gene sequences indicates that synonymous codons are used differently by monocots and dicots. These patterns are also distinct from those reported for $E$. coli, yeast and man $(13,18)$.

In general, the plant codon usage pattern more closely resembles that of man and other higher eukaryotes than unicellular organisms, due to the overall preference for $G+C$ content in codon position III $(13,18)$. Monocots in this sample share the most commonly used codon for 13 of 18 amino acids as that reported for a sample of human genes (18), although dicots favor the most commonly used human codon in only 7 of 18 amino acids.

Several earlier discussions of plant codon usage have focussed on the differences between codon choice in plant nuclear genes and in chloroplasts $(18,23)$. Chloroplasts differ from the nuclear genome of higher plants in that they encode only 30 tRNA species $(29,30)$. Since 
chloroplasts have restricted their tRNA genes, the use of preferred codons by chloroplastencoded proteins appears more extreme. However, a positive correlation has been reported between the level of isoaccepting tRNA for a given amino acid and the frequency with which this codon is used in the chloroplast genome (31).

Our analysis of the expanded plant sample confirms earlier reports that the nuclear and chloroplast genomes in plants have distinct coding strategies. The codon usage of monocots in this sample is distinct from chloroplast usage, sharing the most commonly used codon for only 1 of 18 amino acids. Dicots in this sample share the most commonly used codon of chloroplasts in only 4 of 18 amino acids. In general, the chloroplast codon profile more closly resembles that of unicellular organisms, with a strong bias towards the use of $A+T$ in the degenerate third base.

In unicellular organisms, highly expressed genes use a smaller subset of codons than do weakly expressed genes, although yeast and $E$. coli use distinct preferred codons in some cases. Sharp and $\mathrm{Li} \mathrm{(12)} \mathrm{report} \mathrm{that} \mathrm{codon} \mathrm{usage} \mathrm{in} 165 \mathrm{E}$. coli genes reveals a positive correlation between high expression and increased codon bias. Bennetzen and Hall (15) and others $(12-14,17,18)$ have decribed a similar trend in codon selection in yeast. Codon usage in these highly expressed genes correlates with the abundance of isoaccepting tRNAs in both yeast and E. coli. If, as Ikemura (16) has proposed, the good fit of abundant yeast and $E$. coli mRNA codon usage to isoacceptor tRNA abundance promotes high translation levels and and high steady state levels of these proteins, then the potential for high levels of expression of plant genes in yeast or $E$. coli could be limited by their codon usage. Hoekema et al. (24) report that replacement of the 25 most favored yeast codons with rare codons in the 5' end of the highly expressed gene PGK1 leads to a decrease in both mRNA and protein. These results indicate that codon bias should be considered when engineering high expression of foreign genes in yeast and other systems.

A number of researchers have attempted to express plant genes in yeast (32-34) and $E$. coli (35-37). In the case of wheat $\alpha$-gliadin (32), $\alpha$-amylase (33) genes, and maize zein genes (34), low levels of expression have been reported in yeast. Neill et al. (32) have suggested that the low levels of expression of $\alpha$-gliadin in yeast may be due in part to codon usage bias, since $\alpha$-gliadin codons for Phe, Leu, Ser, Gly, Tyr and especially Glu do not correlate well with the abundant yeast isoacceptor tRNAs. In E. coli, however, soybean glycinin A2 (35) and wheat RuBPC SSU $(36,37)$ are expressed adequately.

Not much is known about the makeup of tRNA populations ir. plants. Viotti et al. (38) report that maize endosperm actively synthesizing zein, a storage protein rich in glutamine, leucine, and alanine, is characterized by higher levels of accepting activity for these three amino acids than are maize embryo tRNAs. This may indicate that the tRNA population of specific plant tissues may be adapted for optimum translation of highly expressed proteins such as zein. To our knowlege, no one has experimentally altered codon bias in highly expressed plant genes to determine possible effects of the protein translation in plants to check the effects on the level of expression. Our data indicate that the highly biased RuBPC SSU and CAB genes would be good candidates for such an experiment.

\section{Acknowlegements:}

We would like to thank Sharon Locken for bibliographic assistance and Lynette Bausch, Lynda Brereton and Sarah Weske for assistance in data entry. 
*To whom correspondence should be addressed

\section{References}

1. Grantham, R. (1980) Trends Biochem. Sci. 5, 327-331.

2. Grantham, R., Gautier, C. and Gouy, M. (1980) Nucl. Acids Res. 8, 1893-1912.

3. Grantham, R., Gautier, C., Gouy, M., Mercier, R. and Pave, A. (1980) Nucl. Acids Res. 8, r49-r62.

4. Grantham, R., Gautier, C., Gouv, M., Jacobzone, M. and Mercier, R. (1981) Nucl. Acids Res. 9, r43-r74.

5. Aota, S.-I., Gojobori, T., Ishibashi, F., Maruyama, T. and Ikemura, T. (1988) Nucl. Acids Res. 16, r315-r402.

6. Ikemura, T. (1981) J. Mol. Biol. 146, 1-21.

7. Gouy, M. and Gautier, C. (1982) Nucl. Acids Res. 10, 7055-7074.

8. Sharp, P.M. and Li., W.-H. (1986) J. Mol. Evol. 24, 28-38.

9. Ogasawara, N. (1985) Gene 40, 145-150.

10. McConnell, D.J., Catwell, B.A., Devine, K.M., Forage, A.J., Laiode, B.M., O'Kane, C., Ollington, J.F. and Sharp, P.M. (1986) Ann. NY Acad. Sci. 469, 1-17.

11. Winans, S.C., Allenza, P., Stachel, S.E., McBride, K.E. and Nester, E.W. (1987) Nucl. Acids. Res. 15, 825-837.

12. Sharp, P.M. and Li., W.-H. (1986) Nucl. Acids Res. 14, 7734-7749.

13. Ikemura, T. (1985) Mol. Biol. Evol. 2, 13-34.

14. Boer, H.A., de and Kastelein, R.A. (1986) In: From Gene to Protein: Steps Dictating the Maximal Level of Gene Expression (eds. J. Davis, B. Reznikoff and L. Gold). Butterworths, New York.

15. Bennetzen, J.L. and Hall, B.D. (1982) J. Biol. Chem. 257, 3026-3031.

16. Ikemura, T. (1982) J. Mol. Biol. 158, 573-597.

17. Sharp, P.M., Touhy, T.M.F. and Mosurski, K.R. (1986) Nucl. Acids Res. 14, 5125-5143.

18. Grantham, R., Perrin, P. and Mouchiroud, D. (1986) Oxford Surveys in Evol. Biol. 3, 48-81.

19. Russell, D.W., Smith, M., Williamson, V.M. and Young, E.T. (1983) J. Biol. Chem. 258, 2674-2682.

20. Hastings, K.E.M. and Emerson, C.P. (1983) J. Mol. Evol. 19, 214-218.

21. Bernardi, G. and Bernardi, G. (1985) J. Mol. Evol. 22, 363-365.

22. Lycett, G.W., Delauney, A.J. and Croy, R.R.D. (1983) FEBS Letters 153, 43-46.

23. Boudraa, M. (1987) Genet. Sel. Evol. 19, 143-154.

24. Hoekma, A., Kastelein, R.A., Vasser, M.A. and Boer, H.A. de (1987) Mol. Cell. Biol. 7, 2914-2924.

25. Martinez, H.M., Katzung, B. and Farrah, T. (1984) Sequence Analysis Programs Manual, University of California, San Francisco.

26. Devereux, J. and Haeberli, P. (1983) Program Library of the University of Wisconsin Genetics Computer Group, Madison, Wisconsin.

27. Grantham, R., Greenland, T., Louail, S., Mouchiroud, D., Prato, J.L., Gouy, M. and Gautier, C. (1985) Bull. Inst. Pasteur. 83, 95-148.

28. Matsuka, M., Kano-Murakami, Y., Tanaka, Y., Ozeki, Y. and Yamamoto, N. (1987) J. Biochem. 102, 673-676.

29. Wakasugi, T., Ohme, M., Shinozaki, K. and Sugiura, M. (1986) Plant Mol. Biol. 7, 385392.

30. Shinozaki, K., Ohme, M., Tanaka, M., Wakasugi, T., Hayashida, N., Matsubayashi, T., Zaita, N., Chonwongse, J., Obokata, J., Yamaguchi-Shinozaki, K., Ohto, C., Torazawa, K., Meng, B.Y., Sugita, M., Deno, H., Kamogashira, T., Yamada, K., Kusuda, J., Takaiwa, F., Kato, A., Tohdoh, N., Shimada, H. and Sugiura, M. (1986) EMBO J. 5 , 2043-2049.

31. Pfitzinger, H., Guillemaut, P., Weil, J.-H. and Pillay, D.T.N. (1987) Nucl. Acids Res. $15,1377-1386$. 
32. Neill, J.D., Litts, J.C., Anderson, O.D., Greene, F.C. and Stiles, J.I. (1987) Gene 55, 303-317.

33. Rothstein, S.J., Lahners, K.N., Lazarus, C.M., Baulcombe, D.C. and Gatenby, A.A. (1987) Gene 55, 353-356.

34. Coraggio, I., Compagno, C., Martegani, E., Ranzi, B.M., Sala, E., Alberghina, L. and Viotti, A. (1986) EMBO J. 5, 459-465.

35. Fuzakawa, C., Udaka, K., Murayama, A., Higuchi, W. and Totsuka, A. (1987) FEBS Lett. 224, 125-127.

36. Vies, S.M. van der, Bradley, D. and Gatenby, A.A. (1986) EMBO J. 5, 2439-2444.

37. Gatenby, A.A., Vies, S.M. van der, and Rothstein, S.J. (1987) Eur, J. Biochem. 168, 227-231.

38. Viotti, A., Balducci, C. and Weil, J.H. (1978) Biochim. Biophys. Acta 517, 125-132.

\section{Appendix I: References for Tables 1 and 2.}

1. Hershey, H.P., Barker, R.F., Idler, K.B., Lissemore, J.L. and Quail, P.H. (1985) Nucl. Acids Res. 13, 8543-8559.

2. Rogers, J.C. Dean, D. and Heck, G.R. (1985) Proc. Natl. Acad. Sci. U.S.A. 82, $6512-$ 6516.

3. Knox, C.A.P., Sonthayanon, B., Chandra, G.R. and Muthukrishnan, S. (1987) Plant Mol. Biol. 9, 3-17.

4. Forde, B.G., Kreis, M., Williamson, M.S., Fry, R.P., Pywell, J., Shewry, P.R., Bunce, N. and Miflin, B.J. (1985) EMBO J. 4, 9-15.

5. Fincher, G.B.,Lock, P.A., Morgan, M.M., Lingelbach, K., Wettenhall, R.E.H., Mercer, J.F.B., Brandt, A. and Thomsen, K.K. (1986) Proc. Nat. Acad. Sci. U.S.A. 83, 20812085.

6. Forde, B.G., Heyworth, A., Pywell, J. and Kreis, M. (1985) Nucl. Acids Res. 13, 7327 7339.

7. Mundy, J. and Rogers, J.C. (1986) Planta 169, 51-63.

8. Ponz, F., Paz-Ares, J., Hernandez-Lucas, C., Garcia-Olmedo, F. and Carbonero, P. (1986) Eur. J. Biochem. 156, 131-135.

9. Gausing, K. and Barkardottir, R. (1986) Eur. J. Biochem. 158, 57-62.

10. Chojecki, J. (1986) Carlsberg Res. Commun. 51, 211-217.

11. Bohlmann, H. and Apel, K. (1987) Mol. Gen. Genet. 207, 446-454.

12. Nielsen, P.S. and Gausing, K. (1987) FEBS Lett. 225, 159-162.

13. Takaiwa, F. Ebinuma, H., Kikuchi, S. and Oona, K. (1987) FEBS Lett. 221, 43-47.

14. Higuchi, W. and Fukazawa, C. (1987) Gene 55, 245-253.

15. Baulcombe, D.C., Huttly, A.K., Martienssen, Barker, R.F. and Jarvis, M.G. (1987) Mol. Gen. Genet. 209, 33-40.

16. Lamppa, G.K., Morelli, G. and Chua, N.-H. (1985) Mol. Cell Biol. 5, 1370-1378.

17. Litts, J.C., Colwell, G.W., Chakerian, R.L. and Quatrano, R.S. (1987) Nucl. Acids Res. 15, 3607-3618.

18. Baulcombe, D.C., Barker, R.F. and Jarvis, M.G. (1987) J. Biol. Chem. 262, 1372613735.

19. Rafalski, J.A. (1986) Gene 43, 221-229.

20. Okita, T.W., Cheesbrough, V. and Reeves, C.D. (1985) J. Biol. Chem. 260 8203-8213.

21. Sugiyama. T., Rafalski, A., Peterson, D. and Sö 1l, D. (1985) Nucl. Acids Res. 13, 8729-8737.

22. Tabata, T., Fukasawa, M. and Iwabuchi, M. (1984) Mol. Gen. Genet. 196, 397-400.

23. Tabata, T. and Iwabuchi, M. (1984) Gene 31, 285-289.

24. Smith, S.M., Bedbrook, J. and Speirs, J. (1983) Nucl. Acids Res. 11, 8719-8734.

25. Kreis, M., Forde, B.G., Rahman, S., Miflin, B.J. and Shewry, P.R. (1985) J. Mol. Biol. $183,499-502$. 
26. Schwarz-Sommer, Z., Shepherd, N., Tacke, E., Gierl, A., Rohde, W., Leclercq, L., Mattes, M., Berndtgen, R., Peterson, P.A. and Saedler, H. (1987) EMBÖ J. 6, 287-294.

27. Shah, D.M., Hightower, R.C. and Meagher, R.B. (1983) J. Mol. Appl. Genet. 2, 111126.

28. Dennis, E.S., Sachs, M.M., Gerlach, W.L., Finnegan, E.J. and Peacock, W.J. (1985) Nucl. Acids Res. 13, 727-743.

29. Kelley, P.M. and Tolan, D.R. (1986) Plant Physiol. 82, 1076-1080.

30. Baker, A. and Leaver, C.J. (1985) Nucl. Acids Res. 13, 5857-5867.

31. Prat, S., Cortadas, J., Puigdomènech , P. and Palau, J. (1985) Nucl. Acids Res. 13, 1493-1504.

32. Moore, R.E. Davies, M.S., O'Connell, K.M., Harding, E.I., Wiegand, R.C. and Tiemeier, D.C. (1986) Nucl. Acids Res. 14, 7227-7235.

33. Chaubet, N., Philipps, G., Chaboute, M.-E., Ehling, M. and Gigot, C. (1986) Plant Mol. Biol. 6, 253-263.

34. Philipps, G., Chaubet, N., Chaboute, M. -E., Ehling, M. and Gigot, C. (1986) Gene 42, 225-229.

35. Rochester, D.E., Winer, J.A. and Shah, D.M. (1986) EMBO J. 5, 451-458.

36. Matsuoka, M., Kano-Murakami, Y. and Yamamoto, N. (1987) Nucl. Acids Res. 15, 6302.

37. Vance, V.B. and Huang, A.H.C. (1987) J. Biol. Chem. 262, 11275-11279.

38. Izui, K. Ishijima, S., Yamaguchi, Y., Katagiri, F., Murata, T., Shigesada, K., Sugiyama, T. and Katsuki, H. (1986) Nucl. Acids Res. 14, 1615-1628.

39. Lebrun, M., Waksman, G. and Freyssinet, G. (1987) Nucl. Acids Res. 15, 4360.

40. Werr, W., Frommer, W.-B., Maas, C. and Starlinger, P. (1985) EMBO J. 4, 1373-1380.

41. Marchionni, M. and Gilbert, W. (1986) Cell 46, 133-141.

42. Geraghty, D.E., Messing, J. and Rubenstein, I. (1982) EMBO J. 1, 1329-1335.

43. Marks, M.D., Lindell, J.S. and Larkins, B.A. (1985) J. Biol. Chem. 260, 16451-16459.

44. Prat, S., Pérez-Grau, L and Puigdomènech, P. (1987) Gene 52, 41-49.

45. Pedersen, K., Devereux, J., Wilson, D.R., Sheldon, E. and Larkins, B.A. (1982) Cell 29, 1015-1026.

46. Marks, M.D. and Larkins, B.A. (1982) J. Biol. Chem. 257, 9976-9983.

47. Bethards, L.A., Skadsen, R.W. and Scandalios, J.G. (1987) Proc. Natl. Acad. Sci. U.S.A. 84, 6830-6834.

48. Paz-Ares, J., Ghosal, D., Wienand, U., Peterson, P.A. and Saedler, H. (1987) EMBO J. 6, 3553-3558.

49. Sommer, H. and Saedler, H. (1986) Mol. Gen. Genet. 202, 429-434.

50. Chang, C. and Meyerowitz, E.M. (1986) Proc. Natl. Acad. Sci. USA 83, 1408-1412.

51. Chaboute, M.-E., Chaubet, N., Philipps, G., Ehling, M. and Gigot, C. (1987) Plant Mol. Biol. 8, 179-191.

52. Leutwiler, L.S., Meyerowitz, E.M. and Tobin, E.M. (1986) Nucl. Acids Res. 14, 40514064.

53. Ludwig,S.R. Oppenheimer, D.G., Silflow, C.D. and Snustad, D.P. (1987) Proc. Nat. Acad. Sci. UU.S.A. 84, 5833-5837.

54. Klee, H.J., Muskopf, Y.M. and Gasser, C.S. (1987) Mol. Gen. Genet. 210, 437-442.

55. Altenbach, S.B., Pearson, K.W., Leung, F.W. and Sun, S.S.M. (1987) Plant Mol. Biol. 8, 239-250.

56. Rose, R.E., DeJesus, C.E., Moylan, S.L., Ridge, N.P., Scherer, D.E. and Knauf, V.C. (1987) Nuc. Acids Res. 15, 7197.

57. Ericson, M.L., Roedin, J., Lenman M., Glimelius, K, Josefsson, L.-G. and Rask, L. (1986) J. Biol. Chem. 261, 14576-14581. 58. Nasrallah, J.B., Kao, T.-H., Goldberg, M.L. and Nasrallah, M.E. (1985) Nature 318, 
59. Carrington, D.M., Auffret, A. and Hanke, D.E. (1985) Nature 313, 64-67.

60. Cohen, L.W., Coghlan, V.M. and Dihel, L.C. (1986) Gene 48, 219-227.

61. Merchant, S. and Bogorad, L. (1987) J. Biol. Chem. 262, 9062-9067.

62. Goldschmidt-Clermont, M., and Rahire, M. (1986) J. Mol. Biol. 191, 421-437.

63. Sharrock, R.A., Lissemore, J.L and Quail, P.H. (1986) Gene 47, 287-295.

64. Smith, S.M. and Leaver, C.J. (1986) Plant Physiol. 81, 762-767.

65. Greenland, A.J., Thomas, M.V. and Walden, R.M. (1987) Planta 170, 99-110.

66. Chen, J. and Varner, J.E. (1985) EMBO J. 4, 2145-2151.

67. Chen, J. and Varner, J.E. (1985) Proc. Natl. Acad. Sci. USA 82, 4399-4403.

68. Schnell, D.J. and Etzler, M.E. (1987) J. Biol. Chem. 262, 7220-7225.

69. Adams, C.A., Babcock, M., Leung, F. and Sun, S.M. (1987) Nucl. Acids Res. 15, 1875.

70. Schuler, M.A., Ladin, B.F., Pollaco, J.C., Freyer, G. and Beachy, R.N. (1982) Nucl. Acids Res. 10, 8245-8261.

71. Hammond, R.W., Foard, D.E. and Larkins, B.A. (1984) J. Biol. Chem. 259, 9883-9890.

72. Negoro, T., Momma, T. and Fukazawa, C. (1985) Nucl. Acids Res. 13, 6719-6731.

73. Momma, T. Negoro, T., Hirano, H., Matsumoto, A., Udaka, K. and Fukazawa, C. (1985) Eur. J. Biochem. 149, 491-496.

74. Fukazawa C., Momma, T., Hirano, H. Harada, K. and Udaka, K. (1985) J. Biol. Chem. 260, 6234-6239.

75. Momma, T., Negoro, T., Udaka, K. and Fukazawa, C. (1985) FEBS Lett. 188, 117-122.

76. Nagao, R.T., Czarnecka, E., Gurley, W.B., Schö ffl, F. and Key, J.L. (1985) Mol. Cell. Biol. 5, 3417-3428.

77. Brisson, N. and Verma, D.P.S. (1982) Proc. Natl. Acad. Sci. USA 79, 4055-4059.

78. Vodkin, L.O., Rhodes, P.R. and Goldberg, R.B. (1983) Cell 34, 1023-1031.

79. Shibata, D., Steczko, J., Dixon J.E., Hermodson, M., Yazdanparast, R. and Axelrod, B. (1987) J.' Biol. Chem. 262, 10080-10085.

80. Sandal, N.N., Bojsen, K. and Marcker, K.A. (1987) Nucl. Acids Res. 15, 1507-1519.

81. Mauro, V.P. Nguyen, T., Katinakis, P. and Verma, D.P.S. (1985) Nucl. Acids Res. 13, 239-249.

82. Katinakis, P. and Verma, D.P.S. (1985) Proc. Natl. Acad. Sci. USA 82, 4157-4161.

83. Jacobs, F.A., Zhang, M., Fortin, M.G. and Verma, D.P.S. (1987) Nucl. Acids Res. 15, 1271-1280.

84. Fortin, M.G., Morrison, N.A. and Verma, D.P.S. (1987) Nucl. Acids Res. 15, 813-824.

85. Nguyen, T., Zelechowska, M., Foster, V., Bergmann, H. and Verma, D.P.S. (1985) Proc. Natl. Acad. Sci. USA 82, 5040-5044.

86. Franssen, H.J., Nap, J.-P., Gloudemans, T., Stiekema, W., van Dam, H., Govers, F., Louwerse, J., van Kammen, A., and Bisseling, T. (1987) Proc. Natl. Acad. Sci. USA 84, 4495-4499.

87. Sengupta-Gopalan, C., Pitas, J.W., Thompson, D.V. and Hoffman, L.M. (1986) Mol. Gen. Genet. 203, 410-420.

88. Hong, J.C., Nagao, R.T. and Key, J.L. (1987) J. Biol. Chem. 262, 8367-8376.

89. Berry-Lowe, S.L. McKnight, T.D., Shah, D.M. and Meagher, R.B. (1982) J. Mol. Appl. Genet. 1, 483-498.

90. Krueger, R.W., Holland, M.A., Chisholm, D. and Polacco, J.C. (1987) Gene 54, 41-50.

91. Czarnecka, E., Nagao, R.T., Key, J.L. and Gurley, W.B. (1988) Mol. Cell Biol. 8, 1113-1122.

92. Vierling, E., Nagao, R.T., DeRocher, A.E. and Harris, L.M. (1988) EMBO J. 7, 575581.

93. Guiltinan, M.J., Ma, D.-P., Barker, R.F. Bustos, M.M., Cyr, R.J., Yadegari, R. and Fosket, D.E. (1988) Plant Mol. Biol. 10, 171-184.

94. Chlan, C.A., Borroto, K., Kamalay, J.A. and Dure, L. (1987) Plant Mol. Biol. 9, 533546. 
95. Waksman, G. and Freyssinet, G. (1987) Nucl. Acids Res. 15, 1328-1328.

96. Allen, R.D., Cohen, E.A., Vonder Haar, R.A., Adams, C.A., Ma, D.P., Nessler, C.L. and Thomas, T.L. (1987) Mol. Gen. Genet. 210, 211-218.

97. Sakajo, S., Nakamura, K. and Asahi, T. (1987) Eur. J. Biochem. 165, 437-442.

98. Karlin-Neumann, G.A., Kohorn, B.D., Thornber, J.P. and Tobin, E.M. (1985) J. Mol. Appl. Genet. 3, 45-61.

99. Stiekema, W.J., Wimpee, C.F. and Tobin, E.M. (1983) Nucl. Acids Res. 11, 8051-8061.

100. Konieczny, A. (1987) Nucl. Acids Res. 15, 6742.

101. Hoffman, N.E., Pichersky, E., and Cashmore, A.R. (1987) Nucl. Acids Res. 15, 3928.

102. Holdsworth, M.J., Bird, C.R., Ray, J., Schuch, W. and Grierson, D. (1987) Nucl. Acids Res. 15, 731-739.

103. Grierson, D., Tucker, G.A., Keen, J., Ray, J., Bird, C.R. and Schuch, W. (1986) Nucl. Acids Res. 14, 8595-8603.

104. Hoffman, N.E., Pichersky, E., Malik, V.S., Castresana, C., Ko, K., Darr, S.C. and Cashmore, A.R. (1987) Proc. Natl. Acad. Sci. U.S.A. 84, 8844-8848.

105. Pichersky, E., Bernatzky, R., Tanksley, S.D. and Cashmore, A.R. (1986) Proc. Natl. Acad. Sci. USA 83, 3880-3884.

106. McKnight, T.D., Alexander, D.C., Babcock, M.S. and Simpson, R.B. (1986) Gene 48, 23-32.

107. Lee, J.S., Brown, W.E., Graham, J.S., Pearce, G., Fox, E.A., Dreher, T.W., Ahern, K.G., Pearson, G.D. and Ryan, C.A. (1986) Proc. Natl. Acad. Sci. USA 83, 72777-7281.

108. Graham, J.S., Pearce, G., Merryweather, J., Titani, K., Ericsson, L.H. and Ryan, C.A. (1985) J. Biol. Chem. 260, 6561-6564.

109. Pichersky, E., Bernatzky, R., Tanksley, S.D., Breidenbach, R.B., Kausch, A.P. and Cashmore, A.R. (1985) Gene 40, 247-258.

110. Pirersky, E., Hoffman, N.E., Malik, V.S., Bernatzky, R., Tanksley, S.D., Szabo, L. and Cashmore, A.R. (1987) Plant Mol. Biol. 9, 109-120.

111. Ray, J., Bird, C., Maunders, M., Grierson, D. and Schuch, W. (1987) Nucl. Acids Res. $15,10587$.

112. Kiss. G.B., Végh, Z. and Vincze, E. (1987) Nucl. Acids Res. 15, 3620.

113. DeRocher, E.J., Ramage, R.T., Michalowski, C.B. and Bohnert, H.J. (1987) Nuc. Acids Res. 15, 6301.

114. Boutry, M. and Chua, N.-H. (1985) EMBO J. 4, 2159-2165.

115. Calza, R., Huttner, E., Vincentz, M., Rouzé , P., Galangau, F., Vaucheret, H., Chérel, I., Meyer, C., Kronenberger, J., and Caboche, M. (1987) Mol. Gen. Genet. 209, 552562 .

116. Tingey, S.V. and Coruzzi, G.M. (1987) Plant Phys. 84, 366-373.

117. Shinshi, H., Mohnen, D. and Meins, F. Jr. (1987) Proc. Natl. Acad. Sci USA (1987) 84, 89-93.

118. Shih, M.-C., Lazar, G. and Goodman, H.M. (1986) Cell 47, 73-80.

119. Pfitzner, U.M. and Goodman, H.M. (1987) Nucl. Acids Res. 15, 4449-4465.

120. Cornelissen B.J.C., Hooft van Huijsduijnen, R.A.M., Van Loon, L.C. and Bol, J.F. (1986) EMBO J. 5, 37-40.

121. Lagrimini, L.M., Burkhart, W., Moyer, M. and Rothstein, S. (1987) Proc. Natl. Acad. Sci. USA 84, 7542-7546.

122. Mazur, B.J. and Chui, C.-F. (1985) Nucl. Acids Res. 13, 2373-2386.

123. Cornelissen, B.J.C., Hooft van Huijsduijnen, R.A.M. and Bol, J.F. (1986) Nature 321, 531-532.

124. Tucker, M.L., Durbin, M.L., Clegg, M.T. and Lewis, L.N. (1987) Plant Mol. Biol 9, 197-203.

125. Reimold, U., Kröger, M., Kreuzaler, F. and Hahlbrock, K. (1983) EMBO J. 2, 18011805.

126. Dunsmuir, P. (1985) Nuc. Acids Res. 13, 2503-2518. 
127. Stayton, M.M., Black, M., Bedbrook, J. and Dunsmuir, P. (1986) Nucl. Acids Res. 14, 9781-9796.

128. Koes, R.E., Spelt, C.E., Reif, H.J., van den Elzen, P.J.M., Veltkamp, E. and Mol, J.N.M. (1986) Nucl. Acids Res. 14, 5229-5239.

129. Condit, C.M. and Meagher, R.B. (1986) Nature 323, 178-181.

130. Tumer, N.E., Clark, W.G., Tabor, G.J., Hironaka, C.M., Fraley, R.T. and Shah, D.M. (1986) Nucl. Acids Res. 14, 3325-3342.

131. Winter, J., Wright, R., Duck, N., Gasser, C., Fraley, R. and Shah, D. (1988) Mol. Gen. Genet. 211, 315-319.

132. Broglie, K.E., Gaynor, J.J. and Broglie, R.M. (1986) Proc. Natl. Acad. Sci. USA 83, 6820-6824.

133. Hoffman, L.M. and Donaldson, D.D. (1985) EMBO J. 4, 883-889.

134. Gebhardt, C., Oliver, J.E., Forde, B.G., Saarelainen, R. and Miflin, B.J. (1986) EMBO J. $5,1429-1435$.

135. Lee, J.S. and Verma, D.P.S. (1984) EMBO J. 3, 2745-2752.

136. Hoffman, L.M. (1984) J. Mol. Appl. Genet. 2, 447-453.

137. Edwards, K., Cramer, C.L., Bolwell, G.P., Dixon, R.A., Schuch, W. and Lamb, C.J. (1985) Proc. Natl. Acad. Sci. USA 82, 6731-6735.

138. Slightom, J.L., Drong, R.F., Klassy, R.C. and Hoffman, L.M. (1985) Nucl. Acids Res. 13, 6483-6498.'

139. Osborn, T.C., Alexander, D.C., Sun, S.S.M., Cardona, C. and Bliss, F.A. (1988) Science 240, $207-210$.

140. Ryder, T.B., Hedrick, S.A., Bell, J.N., Liang, X., Clouse, S.D. and Lamb, C.J. (1987) Mol. Gen. Genet. 210, 219-233.

141. Higgins, T.J.V., Beach, L.R., Spencer, D., Chandler, P.M., Randall, P.J., Blagrove, R.J., Kortt, A.A., and Guthrie, R.E. (1987) Plant Mol. Biol. 8, 37-45.

142. Cashmore, A.R. (1984) Proc. Natl. Acad. Sci. USA 81, 2960-2964.

143. Tingey, S.V., Walker, E.L. and Coruzzi, G.M. (1987) EMBO J. 6, 1-9.

144. Gatehouse, J.A., Brown, D., Evans, I.M., Gatehouse, L.N., Jobes, D., Preston, P. and Croy, R.R.D. (1987) Nucl. Äcids Res. 15, 7642.

145. Lycett, G.W., Croy, R.R.D., Shirsat, A.H. and Boulter, D. (1984) Nucl. Acids Res. 12, 4493-4506.

146. Coruzzi, G., Broglie, R., Edwards, C. and Chua, N.-H. (1984) EMBO J. 3, 1671-1679.

147. Lycett, G.W., Delauney, A.J., Gatehouse, J.A., Gilroy, J., Croy, R.R.D. and Boulter, D. (1983) Nucl. Acids Res. 11, $2367-2380$.

148. Llewellyn, D.J., Finnegan, E.J., Ellis, J.G., Dennis, E.S. and Peacock, W.J. (1987) J. Mol. Biol. 195, 115-123.

149. Gantt, J.S. and Key, J.L. (1987) Eur. J. Biochem. 166, 119-125.

150. Guidet, F. and Fourcroy, P. (1988) Nucl. Acids Res. 16, 2336.

151. Roberts, L.M., Lamb, F.I., Pappin, D.J.C. and Lord, J.M. (1985) J. Biol. Chem. 260, 15682-15686.

152. Halling, K.C., Halling, A.C., Murray, E.E., Ladin, B.F., Houston, L.L. and Weaver, R.F. (1985) Nucl. Acids Res. 13, 8019-8033.

153. Beeching, J.R. and Northcote, D.H. (1987) Plant Mol. Biol. 8, 471-475. 154. Smeekens, S., van Binsbergen, J. and Weisbeek, P. (1985) Nucl. Acids Res. 13, 3179-

155. Smeekens, S., de Groot, M., van Binsbergen, J. and Weisbeek, P. (1985) Nature 317, 456-458.

156. Martin, W. and Creff, R. (1986) Eur. J. Biochem. 159, 323-331.

157. Mignery, G.A., Pikaard, C.S., Hannapel, D.J. and Park, W.D. (1984) Nucl. Acids Res. $12,7987-8000$.

158. Cleveland, T.E., Thornburg, R.W. and Ryan, C.A. (1987) Plant Mol. Biol. 8, 199-207. 
159. Eckes, P., Rosahl, S., Schell, J. and Willmitzer, L (1986) Mol. Gen. Genet. 205, 14-22.

160. Keil, M., Sanchez-Serrano, J., Schell, J. and Willmitzer, L. (1986) Nucl. Acids Res. 14, 5641-5650.

161. Wolter, F.P., Fritz, C.C., Willmitzer, L., Schell, J. and Schreier, P.H. (1988) Proc. Natl. Acad. Sci. USA 85,846-850.

162. Salanoubat, M. and Belliard, G. (1987) Gene 60, 47-56.

163. Scherer, D.E. and Knauf, V.C. (1987) Plant Mol. Biol. 9, 127-134.

164. Jansen, T., Rother, C., Steppuhn, J., Reinke, H., Beyreuther, K., Jansson, C., Andersson, B. and Herrmann, R.G. (1987) FEBS Lett. 216, 234-240.

165. Rother, C., Jansen, T., Tyagi, A., Tittgen, J. and Herrmann, R.G. (1986) Curr. Gen. 11, 171-176.

166. Tyagi, A., Hermans, J., Steppuhn, J., Jansson, Ch., Vater F. and Herrmann, R.G. (1987) Mol. Gen. Genet. 207, 288-293.

167. Volokita, M. and Somerville, C.R. (1987) J. Biol. Chem. 262, 15825-15828.

168. Kuhse, J. and Pühler, A. (1987) Plant Sci. 49, 137-143.

169. Bäumlein, H., Wobus, U., Pustell, J. and Kafatos, F.C. (1986) Nucl. Acids Res. 14, 2707-2720.

170. Bassüner, R., Hai, N.V., Jung, R., Saalbach, G. and Müntz, K. (1987) Nucl. Acids Res. $15,9609$. 